\title{
Persistent Traditional Practices Among the Tribals of North Coastal Andhra Pradesh
}

\author{
P. Durga Rao ${ }^{*}$, M. Sudhakar Babu ${ }^{2}$ and V. L. Narasimha Rao ${ }^{1}$ \\ 1. Department of Anthropology, 2. Population Research Centre, Andhra University, \\ Visakhapatnam 530 003, Andhra Pradesh, India \\ "E-mail: durgarao1973@yahoo.com
}

KEYWORDS Evil spirits; pollution; ritual; fomentation; scars; medicine man

\begin{abstract}
This paper deals with the persistent traditional practices associated with puberty, pregnancy and child birth among the tribal populations of the three north coastal districts of Andhra Pradesh viz. Srikakulam, Vizianagaram and Visakhapatnam. Observation of pollution associated with some vital events among the tribal populations is also related to health. The traditional practices of tribals associated with puberty, pregnancy and child birth have some similarity with the practices of the non-tribals especially in rural areas. All these practices signify their deep rooted beliefs in the supernatural spirits. In this context, the role of traditional medicine-man (Guravagadu) is also prominent. These observations point out the need for educating these groups about health and hygiene and make them avail health care services.
\end{abstract}

\section{INTRODUCTION}

The study of every human group reveals the existence of a unique set of beliefs representing their sub-culture within the total population. These beliefs operate in a meaningful way as far as their cultural life is concerned. Sahay (2001) observed that the age old practices such as attitude towards conception, dietary restrictions, the place of delivery, non-trained birth attendant, the instruments used for cutting the umbilical cord so on, are important determinants of maternal and infant mortality. Hence, these practices need to be understood. Persistence of traditional practices is more among the tribal populations. It is very important to encourage these cultural practices and at the same time these tribal communities should benefit from modern health care services. In the present paper, an attempt is made to discuss some such practices observed among the tribal populations of north-coastal districts of Andhra Pradesh.

\section{MATERIAL}

Traditional practices related to the three major vital events in a woman's reproductive period viz. puberty, pregnancy and child birth, maternal health care during pregnancy and child health care were recorded from tribal women of 3000 households from the three north coastal districts of Andhra Pradesh viz. Srikakulam, Vizianagaram and Visakhapatnam. The predominant tribal groups in this region include Bagatha, Gadaba, Jatapu, Valmiki, Konda Savara, Porja, Khond, Konda Dora. The information is further supplemented by the observations made from informal interviews with some Anganwadi workers, health personnel, teachers and other knowledgeable persons in the field.

\section{OBSERVATIONS}

Tribals generally feel that good health is the outcome of pious and disciplined life while illness is regarded as the punishment given by Gods or spirits. Hence, their health culture is centered around magico-religious practices besides other therapeutic practices. Beliefs associated with vital ceremonies such as puberty, pregnancy and child birth are also popular and these practices are still persistent among these tribal groups.

\section{Puberty}

The age at menarche generally is around 12 years among the tribal girls. On the first day, the maternal aunt makes the girl sit on a bamboo mat or neredu leaves (syzigium cumini) or banana leaves (musa paradisica) or mango leaves even without bathing in a corner of front yard alone. As Reddy (2003) observed, at the time of first 
menstruation, the girl is kept in one corner of the front yard alone for seven days and nights, and no man is allowed to see the girl for these seven days. There is a lot of emphasis on purity and pollution rites among Konda Reddis. The girl is fed with dal rice up to $10^{\text {th }}$ day. On the $3^{\text {rd }}-5^{\text {th }}-7^{\text {th }}$ or $9^{\text {th }}$ day, the girl is given a bath with turmeric powder. After the onset of puberty, the girl is taken into the house either on $3^{\text {rd }}, 5^{\text {th }}, 7^{\text {th }}, 11^{\text {th }}$ or $12^{\text {th }}$ day. Non-vegetarian food is prohibited as long as the girl stays outside the house. Food items made out of vegetables, payasam (a sweet dish) and special dishes prepared with jaggery are given up to $7^{\text {th }}$ day.

Among the Konda Savaras, there is no custom of keeping the girl outside the house after puberty. The maternal aunt makes the girl sit on a jute cloth. Palmyrah leaves (Borassus flabellifera) are placed on the ground and the girl is made to sit on them after bath on the $3^{\text {rd }}, 5^{\text {th }}, 7^{\text {th }}$ or $9^{\text {th }}$ day after puberty.

\section{Pregnancy}

During pregnancy, the pregnant woman is prohibited from visiting the temples, especially Siva temple, as they believe that by doing so she will suffer from Linga Dosham. But the husband can pay visits to the temples. During $5^{\text {th }}$ month of pregnancy, two pots of sara (country liquor) or maddi kallu (rice beer) and chicken are taken round the pregnant woman for three times and left in the village pathway to ward off evil spirits. They believe that pregnancy will be terminated as 'abortion', if such a ritual is not performed in time. If the members of the family had any prior commitment to a god, rituals to any god are performed during $7^{\text {th }}$ month of pregnancy and a chicken or goat will be sacrificed. If the pregnant woman feels restless or impatient, chillies or buffalo's dung is taken round her thrice to ward off evil spirits.

The pregnant woman is given a paste of dates soaked in honey during the night time for normal delivery without any complications. Janmaraja Puja is performed by Janni (wife of guravagadu) during $3^{\text {rd }}$ or $4^{\text {th }}$ month, by sacrificing two chicken for smooth and safe delivery. They believe that delivery would not be smooth if the puja is not performed at the appropriate time. Four species of flowers are taken round the pregnant woman to ward off evil spirits. During the second month of pregnancy, the pregnant woman performs puja to Sattar Ghost by sacrificing chicken. The ritual will be held near a tree in the forest. Rituals by the shaman are quite common to propitiate the Gods and spirits for the well being and for conceiving. The same view is supported by Reddy (2003) from her study on Konda Reddis.

After $3^{\text {rd }}$ month of pregnancy, Bangalani ritual is performed near the stream. The members of the household sacrifice chick or pig and perform puja (ceremony) by offering fruits. The sacrificed animal is eaten or thrown into the stream. During the $6^{\text {th }}$ month of pregnancy, egg, rice husk, and small new cloth (yellow or red colour) are taken around the pregnant woman to ward off evil spirits, and the material is thrown in the stream by a old woman or on the floor near the stream. This ceremony is called Ravulu teerchuta. During $7^{\text {th }}$ or $9^{\text {th }}$ month of pregnancy, Ravulu is given away with ash gourd, coconuts, agarbathi and seven peepal leaves (Ficus religiosa). Ravulu ceremony is performed as per the instructions of the Guravagadu (Shaman). During $8^{\text {th }}$ or $9^{\text {th }}$ month of pregnancy, Sannalu puja is performed with lime powder, coconuts, chick, chickpea, jaggery and bananas and the material is thrown on the pathway. They also worship Puli devudu (Tiger God) or 'Konda devudu' (Hill God) for safe delivery and sheep or goat will be sacrificed.

\section{Child Birth}

The timing of giving bath to the mother and the new born after delivery is not uniform among different tribals. Majority have reported that mother and child are given bath on $3^{\text {rd }}, 5^{\text {th }}, 7^{\text {th }} 9^{\text {th }}$ and $11^{\text {th }}$ day respectively after birth of the child while some reported that the mother and child are given bath on the day of delivery. After bath, the child is fed with honey/crystal sugar mixed with hot water for 1-3 days. They believe that breast milk is not produced till $3^{\text {rd }}$ day of the delivery. Breast-feeding commences from $4^{\text {th }}$ day onwards because mother is not given food up to three days after delivery. The tribals strongly believe that feeding of the child with early breast milk leads to indigestion among children. Hence, initially they feed the baby with breast milk of another lactating mother.

On the first day of delivery, mother is given a bath down the trunk. A cloth is tied tightly below the navel to prevent enlargement of the belly. The tribals believe that belly increases in size if the cloth is not tied properly. 
Babu (1998) observed that among the tribals, food is not given to the new mother for 1 or 2 days. Some of the usual items like Jeelakarra Podumu, Chonti (dried ginger) and Salt consumed till one month of the delivery. On the third day, mother is fed with pippalla kayam which is made out of a mixture of Asafotida and Piper longum, ginger, pepper (Piper nigrum), jaggery and gingili oil. This mixture is given to the mother thrice a day. From the $3^{\text {rd }}$ day on wards, mother is fed with dry rice. They believe that nursing mother develops strong trunk and produce rich breast milk if she eats pippalla kayam. The nursing mother is fed with a mixture of oil, turmeric powder, red gram dal, dry rice and brinjal curry (Solanum melangena) up to $9^{\text {th }}$ day after child birth. Observations made by Babu (1998) also confirmed preference for certain foods during post-natal period. The preferred food for new mothers are leafy vegetables, birakaya (bottle gourd), donda kaya (donda) and benda kaya (lady finger).

The nursing mother is allowed to take bath with hot water mixed with turmeric powder and Vayila leaves. Vayila Neellu will be prepared using bamboo leaves (bamboosa), kodavali kokkula leaves (Accasia auriculiformis), Somida bark (Somida febrifuga) and vayila leaves (vitex nigundo) boiled in hot water. This type of bath is called Vayila Neella Snanam.

Boddu puja (umbilical chord ceremony) will be performed on $6^{\text {th }}$ or $8^{\text {th }}$ or $11^{\text {th }}$ day after birth. Naming ceremony is performed on either $3^{\text {rd }}, 9^{\text {th }}$, $11^{\text {th }}, 12^{\text {th }}, 15^{\text {th }}$ or $21^{\text {st }}$ day by Guravagadu (local priest). If the nursing mother has any prior commitments to god during pregnancy, umbilical chord ceremony will be performed by sacrificing goat, chick or pig and coconuts at the place where the umbilical chord is buried in the soil.

The early breast milk of mother is squeezed out before the child is fed with breast milk. Gingili oil will be applied on child's body during fomentation/body warming.

Among Konda Savaras, both child and mother are given bath continuously with turmeric powder up to $5^{\text {th }}$ day after delivery. The child is fed with breast milk on the first day after delivery. Among Konda Savaras, there is no practice of body warming/fomentation of the body among children. Mother is taken inside the house on fifth day after delivery.

Due to fear of attacks from evil spirits, pollution will be observed up to eight days after delivery. On the $2^{\text {nd }}$ day after birth and before the child is fed with breast milk, they use quill of a chicken to pierce a chick's ear from left ear to right ear and the hair strands of chick's quill are tied to the body of all members of the household.

Delivery rites are performed after three days of delivery. Chicken is sacrificed and consumed and earthen lamp is lighted. Prayer is performed on the first day after delivery. After one-month of delivery, Gedda Kanapatam is performed. During this ceremony, mother is taken to the stream for bath. There, she worships the god with chickpea and jaggery. After the completion of this ceremony, mother is allowed to go to the stream for bringing water. The ceremony is performed for greater strength to mother in the performance of daily household work.

\section{Food Items Preferred and Avoided During Pregnancy and After Delivery}

Among the tribal populations, certain food items are preferred for consumption and some are avoided during pregnancy as well as after the delivery as per their customs and beliefs.

Foods Preferred: Bottle gourd, Ridge gourd, Small gourd, Pumpkin, Drumstick, Lady fingers, Plantain, Cauliflower, Beans, Dry mango pieces, Mestha (Hibiscus Cannabinus), Amaranthus, Bamboo shoots, Jute leaves (Gongura), Fruits (Yam/Papaya), Dates, Niger seed oil, Asafoetida, (Black gram, Bengal gram, Pepper, Bread, Milk, Meat (chicken/goat/cattle), Prawn powder, Ragi gruel, Sama gruel, Tamarind rasam, Pippalla kayam, Fried rice with jeera and chilly powder.

Foods Avoided: Bitter gourd, Snake gourd, Potato, Fresh Tamarind, Coconut, Cabbage, Chickpea, Momordiadioca, Cucumissativa, Jack, Mango, Water melon, Fish (dry/raw/salted), Meat (white chicken/wild cat), Wild hog/deer/peacock, Eggs, Maize, Green gram, Bobbarlu (Dolicho Sps.), Asmola dal, Dolichos dal, Barley, Curd (Buffalo), Junnu (Sweet made of first milk of Cattle), Country liquor, Jeelugu kallu (carryota palm sap) and Tablets (except IFA). Prohibited foods during pregnancy are Gummadi kaya (pumpkin), Pesara (green gram), Bobbasikaya (papaya), Puttakokku (mushrooms), Vankaya (brinjal) and Tomato. Similar observations were reported by Babu (1998).

\section{Traditional Child Care Practices}

The following are certain traditional practices 
associated with child care. Body massaging of the child with coconut/ mustard/gingili oil, turmeric powder, black gram and rice flour or chickpea powder is observed both in the morning and evening up to the stage where the child walks independently. The massaging will be done with a paste made out of grinding turmeric with gingili oil. If the child suffers from vomitings, castor oil taken with chicken's quill will be taken round the child and slight massaging will be done on the head to control vomitings.

Majority of tribals put Churakalu (body scars) on child's belly during third month of birth with hot iron rod. They believe that the scars protect the child from worm infestation of stomach, digestion problems and liver cirrhosis. They further believe that if the scars are not put at the appropriate time, the child suffers from worm infestation due to sweetness of early breast milk. Chedu mandu (Sour medicine) is given to the baby from $20^{\text {th }}$ day onwards, thrice a day and up to one year. It is prepared by heating jeera with lime leaf, turmeric and hot water made into paste and administered to the child with breast milk to easy digestion and worm infestation.

Honey mixed with salt is fed to the baby for good complexion and health. If the child suffers from yellow motions, pippallu (piper longum) and pepper powder is ground into a paste and fed to the mother. This is locally called Talakattu mand $u$ and the nursing mother consumes the same at times of need. If the child is unable to digest mother's milk, carum, neem bark and salt will be grinded, boiled in water and fed to the baby. If the baby suffers from respiratory problems or cold and cough, entire body especially belly and chest region is fomented with ippa (Mohwa) oil which is extracted from Mohwa seeds (Bassica longifolia).

\section{CONCLUSION}

The traditional practices reported among the tribal populations associated with puberty, pregnancy and child birth have some similarity with the practices observed among non-tribal groups especially in rural areas. The urban areas have changed a lot and come a long way from the concepts of pollution etc. However, all these persistent practices have some significance with health care and also signify their deep rooted beliefs attached to the supernatural spirits by way of appeasing them with the observation of ceremonies associated with sacrifice etc. The role of traditional medicine man (Guravagadu) is also prominent.

These observations point out the need for educating these groups in the areas of health and hygiene and introducing them to the available health care services. According to Nayak and Babu (2003), the tribal health culture and health seeking behaviour are not free from superstition and taboos, scientific health education and health awareness programmes are required to bring the pivotal change among the tribes. However, it is suggested that the planners and programme managers should develop a strategy to promote the interventions, simultaneously encouraging their traditional practices. Reddy (2003), is also of the opinion that indigenous practitioners will have to be incorporated in health care planning and Anthropological studies are essential for enhancing our understanding to help the tribal to plan their own health care. Practices which are harmful need to be discouraged and good practices are to be encouraged. If necessary, the services of traditional medicine men can be utilized in educating and exposing these groups to the modern interventions and available services.

\section{ACKNOWLEDGEMENTS}

The data incorporated in this paper forms part of the findings of a research project funded by the Ministry of Tribal Affairs, Government of India,(No.10525/22/2000 TD (R) dt.29.3.2000).The authors acknowledge the help rendered by the Ministry for undertaking the project.

\section{REFERENCES}

Babu, K.S. 1998. "Illness and Health Care in Madugula Mandal of Andhra Pradesh," Man in India, 78(3 \& 4): 255-268.

Nayak, A.N and B.V.Babu 2003. "Tribal Health Problems: An Anthropological Appraisal." Man in India, 83 (3 \& 4): 301-313.

Reddy Bharati, Sunita. 2003. "Beliefs and Practices Related to Parturition among the Konda Reddis of Andhra Pradesh," Man in India, 83(3 \& 4): 315336.

Sahay, Sarita 2001. "Cultural Determinants of Maternal and Infant Mortality in Madhya Pradesh." Man in India, 81 (3 \& 4): 363-375. 